\title{
Extrahepatic Bile Duct Neuroendocrine Carcinoma
}

National Cancer Institute

\section{Source}

National Cancer Institute. Extrahepatic Bile Duct Neuroendocrine Carcinoma. NCI

Thesaurus. Code C96956.

An aggressive, high-grade and poorly differentiated carcinoma with neuroendocrine

differentiation that arises from the extrahepatic bile ducts. The mitotic count is more than 20 per $10 \mathrm{HPF}$. According to the size of the malignant cells, the prominence of the nucleoli, and the amount of cytoplasm, it is classified either as small or large cell neuroendocrine carcinoma. 